\title{
Hypertension in pregnancy and statistical power
}

$\mathrm{H}$ ypertension in pregnancy is a major cause of maternal and fetal morbidity. ${ }^{1}$ Preeclampsia, eclampsia, intrauterine growth retardation, and perinatal mortality are adverse effects associated with hypertension.

Approximately 10 percent of pregnant women are at risk for complications attributable to high arterial blood pressure. ${ }^{2}$ Although the treatment of hypertension reduces the maternal risks, ${ }^{3}$ the benefits for the fetus are not yet clear. $^{4}$

The treatment of hypertension crises, one of the most dangerous types of hypertension in pregnancy may be obtained with efficacy using low dose nifedipine ( $5 \mathrm{mg}$ per oral), or hydrazaline (5 mg IM). Reducing the dosage is aimed at decreasing the risks of maternal hypotension and fetal death. ${ }^{5.6}$

Both drugs have about 90 percent efficacy in reducing blood pressure, but it is not known wich drug carriers less risk of adverse effects for the fetus. Suppose that one percent of fetal deaths could be attributed to one drug, and the other drug could be attributed with 0.5 percent; that means a 50 percent less chance of fetal deaths. In order to have $\mathbf{9 0}$ percent power to detect the refered difference on the fetal attributable mortality rate to each of these drugs, a study of 14,000 women with hypertensive crises would be required.?

Although doing a randomized clinical trial of such magnitude would be very difficult, it would certainly not be impossible - if the question were considered relevant for researchers, and more importantly, for funders. Similar situations, as are the cases of drugs adverse effects are

* $M D, P h D, M S c$

Department of Internal Medicine, Escola Paulista de Medicina Chairman, Editor, São Paulo Medical Journal. common in medical literature, and important because they represent human suffering and death.

A proposal for a randomized clinical trial has been prepared by the Eclampsia Trial Group, aimed at comparing magnesium sulfate with placebo. The sample size is estimated at 14,000 cases. The trial would be collaborative, with various groups in Europe and developing countries participating. The effort is worthwhile, as the prevention of eclampsia could prevent about 50,000 maternal deaths annually, 99 percent of which occur in the developing world. ${ }^{8}$

\section{REFERENCES}

1. Davies AM. Epidemiology of hypertensive disorders of pregnancy. Bull WHO 1979;57:373.

2. Atallah AN, Souza Mesquita MR, et al. Estudo prospectivo cohort de gestantes com hipertensão arterial crônica. J Bras Nefrol 1990;12:113-20.

3. Redman CWC. Treatment of hypertension in pregnancy. Kidney Int 1980;18:259.

4. Zuspan FP. Chronic hypertension in pregnancy. Cli Obstet Gynecol 1984;27(4):684.

5. Walss RRJ, Luz MFPGRA. Management of severe preeclampsia/eclampsia: A comparison between nifidipine and hydralazine as antihypertensive drugs. Ginecol Obstet Mex 1993;61:76-9.

6. Atallah AN, Souza Mesquita MR, Kenji G, et al. Estudo randomizado controlado da hidralazina e da nifedipina nas crises hipertensivas na gestatção. Rev Bras Ginecol Obstet 1989;12:10-14.

7. Bulpitt CJ. How many subjects are required for a trial? In: Bulpitt CJ, ed. Randomized controlled clinical trials, Boston, London: Martinus Nishoff, 1983:96-118.

8. The Eclampsia Trial Collaborative Group. Which anticonvulsant with eclampsia? Evidence from the Collaborative Eclampsia Trial. Lancet 1995;345:1455-63. 